\title{
Thyroid Gland Macrofollicular Adenoma
}

National Cancer Institute

\section{Source}

National Cancer Institute. Thyroid Gland Macrofollicular Adenoma. NCI Thesaurus. Code C4161.

A thyroid gland adenoma composed of large size follicles. 